
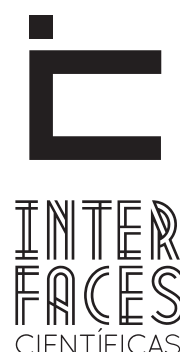

HUMANASE SOCIAIS

\title{
HISTÓRIA E MEMÓRIAS VINCULADAS A BEATA DULCE DOS POBRES EM SÃO CRISTÓVÃO/ SERGIPE [1933/1934]
}

Ivan Rêgo Aragão ${ }^{1}$

\section{RESUMO}

Um fato quase desconhecido pela história das religiões e práticas de religiosidades no Brasil é a presença de Maria Rita de Souza Brito Lopes Pontes, Irmã Dulce, na cidade de São Cristóvão em Sergipe entre os anos de 1933 e 1934. Nesse período, a Beata ainda adolescente, permaneceu na primeira capital de Sergipe para estudos do noviciado, junto à Congregação das Irmãs Missionárias da Imaculada Conceição da Mãe de Deus instalada no Convento de Nossa Senhora do Carmo. A partir da análise documental de cartas que ela endereçou a Elisabeth Maria Gertrudes Tombrock, fundadora e Madre Superiora da Congregação das Irmãs Missionárias da Imaculada Conceição,
José Thiago da Silva Filho entrevistas, pesquisa digital, bibliográfica e trabalho de campo, desenvolvemos o artigo cujo objetivo principal é tratar da relação de Irmã Dulce e São Cristóvão. Foram registrados momentos na vida da religiosa católica, sua permanência na cidade, demarcando os lugares de memória, vinculados a sua estadia para os estudos preparatórios. Ela foi beatificada em 2011 e poderá se tornar a primeira santa católica brasileira.

\section{PALAVRAS-CHAVE}

Lugares de Memória. Irmã Dulce. São Cristóvão/SE. 


\section{ABSTRACT}

A fact almost unknown in the history of religions and religiosity practices in Brazil is the presence of Maria Rita de Souza Brito Lopes Pontes, Sister Dulce, in São Cristóvão Sergipe between the years 1933 and 1934. During this period, Beata a teenager, remained in the first capital of Sergipe for novitiate studies at the Congregation of the Missionary Sisters of the Imaculada Conceição da Mãe de Deus installed in the Convent of Nossa Senhora do Carmo. From the documentation and letters she addressed to Elisabeth Maria Gertrudes Tombrock, founder and Mother Superior of the Congregation of the Missionary Sisters of the Imaculada Conceição, interviews, digital research, bi- bliographic and field work, we developed the product whose main goal is to treat the relationship Sister Dulce and Saint Cristopher. Times were recorded in the Catholic religious life, his stay in the city, marking places of remembrance, bound to stay for preparatory studies. She was beatified in 2011 and could become the first Brazilian Catholic saint.

\section{KEYWORDS}

Memory Seats. Sister Dulce. São Cristóvão/Sergipe.

\section{RESUMEN}

Un hecho casi desconocido por la historia de las religiones y las prácticas de religiosidades en Brasil es la presencia de Maria Rita de Souza Brito Lopes Pontes, Hermana Dulce, en la ciudad de São Cristóvão en Sergipe entre los años de 1933 y 1934. Durante este período, la Beata como todavía adolescente, permaneció en la primera capital de Sergipe para los estudios del noviciado, junto a la congregación de las Hermanas Misioneras de la Inmaculada Concepción de la Madre de Dios, instalada en el Convento de Nossa Senhora do Carmo. A partir del análisis documental de cartas de ella dirigidas a Elisabeth Maria Gertrude Tombrock, fundadora y Madre Superiora de la Congregación de las Hermanas Misioneras de la Inmaculada
Concepción, entrevistas, búsqueda digital, bibliográfica y trabajo de campo, hemos desarrollado el artículo cuyo propósito principal es tratar la relación de la Hermana Dulce y São Cristóvão. Fueron grabados momentos de la religiosa católica, su estancia en la ciudad, marcando los sitios en la memoria, vinculados a su estancia para los estudios preparatorios. Ella fue beatificada en 2011 y podrá ser la primera santa católica brasileña.

\section{PALABRAS CLAVE}

Sitios en la memoria. Hermana Dulce. São Cristóvão/SE. 


\section{INTRODUÇ̄̃̃O}

À Olga Braga dos Santos (1922/2015), in memoriam, que dividiu momentos da sua juventude com "Dulcinha", nas dependências do Convento do Carmo.

A cidade de São Cristóvão foi a capital de Sergipe até 0 ano de 1855. Reconhecida patrimônio histórico nacional em 1938, afamada quarta cidade mais antiga do país, ostenta um rico patrimônio material representado por um conjunto de igrejas e conventos que remontam os séculos XVII e XVIII. A Praça São Francisco, localizada no centro histórico, recebeu a chancela da UNESCO em 2010 como Patrimônio da Humanidade. Os bens culturais de natureza imaterial pertencente à cidade como o folclore, a gastronomia e o artesanato são igualmente relevantes pela historicidade e originalidade.

No entanto, um fato olvidado é a temporada que a Irmã Dulce passou na cidade como noviça. Uma estadia curta entre 1933 e 1934, mas essencial na vida da religiosa que foi instalada no Convento de Nossa Senhora do Carmo, recebendo o hábito da Congregação das Irmãs Missionárias da Imaculada Conceição da Mãe de Deus.

Para elaboração desta pesquisa consultamos as cartas que Irmã Dulce endereçou a Elisabeth Maria Gertrudes Tombrock, arquivadas nas Obras Sociais Irmã Dulce (OSID) ${ }^{4}$ e entrevistas que Olga Braga dos Santos e Irmã Maria das Neves concederam ao historiador José Thiago da Silva Filho, ao documentarista Daniel Barjas e Osvaldo Gouveia Ribeiro. O objetivo é desvelar a relação da Irmã Dulce e São Cristóvão.

Para ampliar a discussão, foi realizada pesquisa bibliográfica para o aporte teórico sobre memória (HALBWACHS, 2004; MENEZES, 1992; POLLACK, 1992) e lugares de memória (NORA, 1993), além de pesquisa digital e trabalho de campo. Biografaram-se momentos específicos na vida da religiosa católica, sua per-

4. Localizadas à Avenida Bonfim, 161, Largo de Roma, Salvador - Bahia. manência na cidade, demarcando lugares vinculados a sua permanência para os estudos de noviciado.

Ela foi beatificada em 2011, podendo tornar-se a primeira santa católica brasileira.

\section{IRMÃ DULCE EM SÃO CRISTÓVÃO}

Maria Rita de Souza Brito Lopes Pontes nasceu na cidade de Salvador em 26 de maio de 1914 (Figura 1). Aos sete anos perdeu sua mãe, realizando nesse mesmo ano sua primeira comunhão na Igreja Santo Antônio na capital baiana. Aos 19 anos, em fevereiro de 1933,

[...] logo após a sua formatura como professora, Maria Rita entra para a Congregação das Irmãs Missionárias da Imaculada Conceição da Mãe de Deus, na cidade de São Cristóvão, em Sergipe. Em 13 de agosto de 1933, recebe o hábito de freira das Irmãs Missionárias e adota, em homenagem a sua mãe, o nome de Irmã Dulce ${ }^{5}$.

Figura 1 - Irmã Dulce aos 2 anos

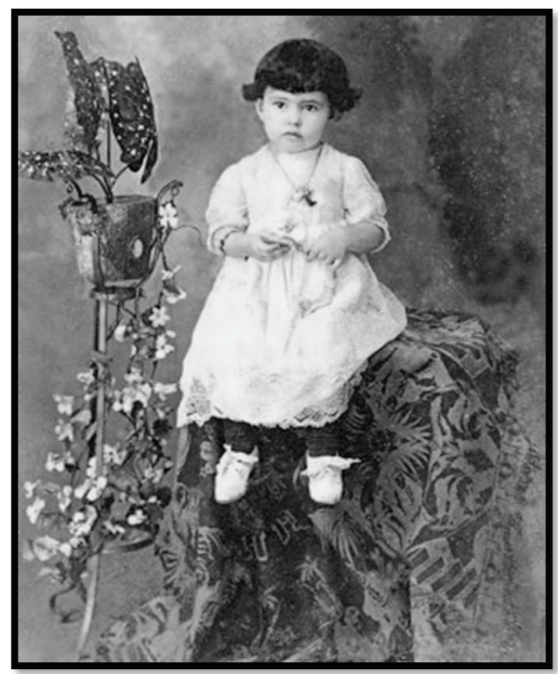

Fonte: https://www.irmadulce.org.br

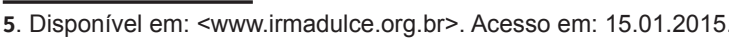


A respeito das motivações que conduziram a Irmã Dulce a São Cristóvão, quando jovem, percebemos que o Convento de Nossa Senhora do Carmo, fundado no início do século XVII, é tradicionalmente espaço de escola de formação de diversas ordens religiosas.

Na segunda metade do século XIX, no episódio conhecido como Questão Religiosa, os carmelitas foram obrigados a deixarem os seus templos por determinação de D. Pedro II. Durante o século XX o convento abrigou outras instituições religiosas. Nele, foi instalada a escola de formação das Irmãs Clarissas Concepcionistas (década de 1920), das Irmãs da Imaculada Conceição (década de 1930) e das Irmãs Beneditinas Enclausuradas. Somente em 2003, o templo carmelita retornou a jurisdição da Ordem Carmelita e ainda hoje é escola de formação da mesma ordem. Posto isso, é compreensível que o destino da postulante a congregação da Imaculada Conceição tenha sido a cidade de São Cristóvão.

Ela só retornaria à terra natal em 1934, depois de cumprir o postulantado e o noviciado, no período de 1 ano e 5 meses, quando foi batizada com o nome Dulce (13 de agosto de 1933), homenagem à mãe falecida, e recebeu o hábito da congregação das Irmã da Imaculada Conceição (IMIC). De volta a Salvador, a "Santa dos Pobres", como ficaria conhecida, viveu a radicalidade do evangelho e a caridade até 1992, ano do seu falecimento. A Irmã Dulce foi indicada ao Prêmio Nobel da Paz, em 1988.

A beatificação da Irmã Dulce foi assinada pelo Papa Bento XVI, em 2011, em razão de um milagre que se deu mediante sua interseção. $O$ fato aconteceu na cidade sergipana de Itabaiana e foi reconhecido pela Comissão Eclesiástica do Vaticano (REDE BAHIA, 2011). 0 primeiro milagre da Beata Dulce dos Pobres repercutiu na imprensa do Brasil e exterior ampliando a visibilidade da religiosa.

Embora as Obras Sociais Irmã Dulce (OSID), sediadas em Salvador, repute o Convento de Nossa Senhora do Carmo, em São Cristóvão, enquanto marco-zero do roteiro da vida da beata Dulce dos Pobres, a memória da sua estadia era completamente desconhecida de turistas, fiéis, comunidade católica local e até mesmo dos simpatizantes da religiosa.

\section{EPISTOLÁRIO DE IRMÃ DULCE}

Irmã Dulce permaneceu em São Cristóvão entre 9 de fevereiro de 1933 e 15 de agosto de 1934. De acordo com Fragata (2008), nesse período, escreveu três cartas para Maria Imaculada de Jesus, nome de Elisabeth Maria Gertrudes Tombrock, fundadora e Madre Superiora da Congregação das Irmãs Missionárias da Imaculada Conceição (IMIC), que estava no Convento de São Boaventura, em Nova York (FRAGATA, 2008). 0 tema das missivas é variado.

Na primeira carta, com data de 19 de março de 1933, ela expõe o contentamento por estar no Convento do Carmo, a emoção e gratidão por estar usando hábito com as cores da vestimenta de Nossa Senhora; satisfação do novo batismo com o nome da sua mãe e, por fim, sua profissão e votos. Na primeira carta, Irmã Dulce registra que tem "[...] immenso prazer, de vos escrever, do meu tão desejado Convento do Carmo" 6 . $\mathrm{Na}$ segunda, a religiosa fala do estado de euforia em pertencer à congregação:

[...] a bôa Madre, do querido e desejado Noviciado. Quanto é bom o nosso Jesus, em conceder esta graça, tão significante, a mim pobre creatura, escolhendo-me para ser sua noivinha! Sinto-me tão feliz, minha bôamãesinha, por pertencer a nossa Congregação e de vestir o habito, que representa as côres da vestimenta da nossa Mãe do Céo!

O epistolário se encontra arquivado nas Obras Sociais Irmã Dulce (OSID) em Salvador e integraram o Processo Histórico de Beatificação de Irmã Dulce, desvelando "o cotidiano, os afazeres, as brincadeiras,

6. Carta de Irmã Dulce para Elisabeth Maria Gertrudes Tombrock. 7. Carta de Irmã Dulce para Elisabeth Maria Gertrudes Tombrock. 
a homilia e a visão de mundo da adolescente Maria Rita Lopes Pontes durante a primeira fase da sua formação religiosa" (FRAGATA, 2008, p. 341). Na terceira e última carta, a religiosa comenta:

[...] Reverenda Madre, quero dizer-vos a grande graça, que Jesus me deu, de eu fazer a Santa Profissão, na presença do meu papai, que Jesus trouxe para assistir o grande dia! E mais do que isto, fiquei alegre, por vel-o receber o meu Divino Esposo, na Santa Communhão. Sim, logo depois que o Santissimo ficou Exposto, papai o recebeu em seu coração. Elle ficou aqui até a Quinta-feira, e d'aqui, seguio para Aracajú, indo de lá a Recife e a Maceió, depois voltará a Bahiå .

Percebe-se a relevância das cartas principalmente por ilustrar os primeiros anos da beata, sua condição neófita na congregação das Irmãs da Imaculada Conceição da Mãe de Deus, seu contato com a cidade. Nesse contexto, os documentos,

[...] constituem fonte preciosa de informações aos historiadores. De forma explícita (datas, nomes, local etc) ou implicitamente (cotidiano, liturgia, o silêncio etc) as impressões facultam substanciar pesquisas diversas. Numa linguagem cinematográfica, a narrativa revela flashes de uma vida que teve São Cristóvão como cenário. (FRAGATA, 2008, p. 344).

Nos curto período de tempo que Irmã Dulce permaneceu em São Cristóvão estabeleceu uma rotina de estudos e afazeres diários, vistos pela neófita “[...] como pequeninos atos de amor que realiza feliz como uma criancinha” (FRAGATA, 2008, p. 343).

O conjunto carmelita que abrigas as igrejas da ordem segunda, terceira e convento é o principal objeto das lembranças, inclusive de quem conviveu com a religiosa baiana. Em entrevista, a senhora Olga Braga dos Santos, 93 anos, conta que: "[...] grande amiga da noviça Maria Rita lembra emocionada dos seus afazeres, como tocar o sino, tirar água da fonte, limpar o chão, das orações; lembra ainda da boneca Célica, o brinquedo inseparável da religiosa baiana"9.

\section{Idem}

9. Entrevista concedida a José Thiago da Silva Filho, São Cristóvão, 14/11/2006
No depoimento da Irmã Maria das Neves "o sítio" era o lugar do lazer, dos risos, da comunicação, das brincadeiras, mas também da oração ${ }^{10}$. No interior do secular convento as práticas pediam austeridade, o voto de silêncio era frequente. A partir do contexto da vida e memória de Irmã Dulce apresentaremos os locais anteriormente mencionados como espaços potenciais de atração do turismo religioso em São Cristóvão.

\section{LUGARES DE MEMÓRIA DE IRMÃ DULCE}

Ao refletir sobre os lugares que produzem lembranças a respeito de fatos ou pessoas dentro do contexto da produção histórica, é possível perceber elementos referenciais de identidade e pertencimento da sociedade, pelo viés das memórias coletivas. É na atualidade que essa memória é demandada, visto que, ela "se dá no presente e para responder as solicitações do presente” (MENEZES, 1992, p. 11). A memória é invocada para suprir necessidades, a fim de dar suportes às sociedades contemporâneas, trazendo consigo fatores de perpetuação. A memória coletiva em uma comunidade aparece como

[...] um elemento constituinte do sentimento de identidade, [...] na medida em que ela é também um fator extremamente importante do sentimento de continuidade e de coerência de uma pessoa ou grupo em sua reconstrução de si. (POLLAK, 1992, p. 5).

A passagem de Irmã Dulce por São Cristóvão para os estudos do noviciado produziu lugares de memória sobre a religiosa, potencialmente atrativos para quem é devoto da Beata ou possui curiosidade em conhecer a sua biografia. Esses locais que reportam à vida de Irmã Dulce são relevantes, na medida em que, traduzem a necessidade humana de estabelecer espaços de referência, numa tentativa de preservar o passado como herança e conservar a identidade cultural (NORA, 1993).

10. Entrevista concedida a Osvaldo Gouveia Ribeiro. João Pessoa/PB, 16 de abril de 2000. Documento integra o Processo Histórico de Beatificação de Irmã Dulce. Assessoria da Memória e Cultura das Obras Sociais Irmã Dulce (OSID). 
A reconstrução do passado por meio da memória perpassa pelas recordações que são comuns a um grupo que experienciam fatos vinculados a um feito ou vulto religioso. A partir da vivência grupal, a memória dos acontecimentos relativos à passagem de Irmã Dulce em São Cristóvão, se presentifica pela lembrança individual e coletiva, sendo o ato de rememorar compartilhado por meio das mesmas experiências (HALBWACHS, 2004).

Eleger lugares para cultuar a memória e evidenciar fatos bíblicos ou a hagiografia dos santos e beatos, renovando os sentimentos de devoção em favor do catolicismo, produzindo o patrimônio da fé católica. Dessa forma o conjunto carmelita com a igreja, convento, gruta/horto e a sala dedicada à memória de Irmã Dulce, apontam para lugares atrativos não somente pela beleza artística e arquitetônica do patrimônio construído, mas por ser local de passagem de uma das maiores representantes da Igreja Católica no Brasil, considerada "a religiosa do século XX" (REVISTA ISTO É, 2000).

\subsection{CONVENTO DO CARMO}

0 conjunto carmelita edificado por esta Ordem religiosa católica, entre os séculos XVII e XVIII, é composto pela igreja do Carmo Grande, tendo a esquerda o convento e a direita antiga igreja da Ordem $3^{a}$ do Carmo, conhecida como Carmo Pequeno ou Igreja do Senhor dos Passos. A Igreja Conventual do Carmo foi edificada primeiro que as outras partes do complexo arquitetônico (ORAZEM, 2006).

0 monumento tem frontão $0^{11}$ em estilo barroco decorado em pedra calcária ostentando o escudo da Ordem Carmelita. A fachada possui três arcos de entrada para a galilé ${ }^{12}$ e o mesmo número de janelas na altura do coro. Segundo Carvalho (1989), no passado,

11. Conjunto arquitetônico de forma triangular que decora o topo da fachada principal de um edifício.

12. Elemento da arquitetura religiosa que remete a galeria entre a parede do frontispício e a porta da nave nalgumas igrejas. a igreja possuía seis altares com os retábulos em talha dourada do século XVIII. Atualmente possui apenas um original. Merece destaque os elementos artísticos fitomórfos, concheados e volutas na sua fachada.

\subsection{MEMORIAL IRMÃ DULCE}

A inauguração do Memorial Irmã Dulce, numa das salas do convento ocorreu em 4 de abril de 2009, numa parceria da ordem carmelita, à época gerida pelo Prior João José Costa, as Obras Sociais Irmã Dulce e a Prefeitura Municipal de São Cristóvão (Figura 2).

Figura 2 - Sala do Memorial Irmã Dulce, no Convento do Carmo, São Cristóvão/SE

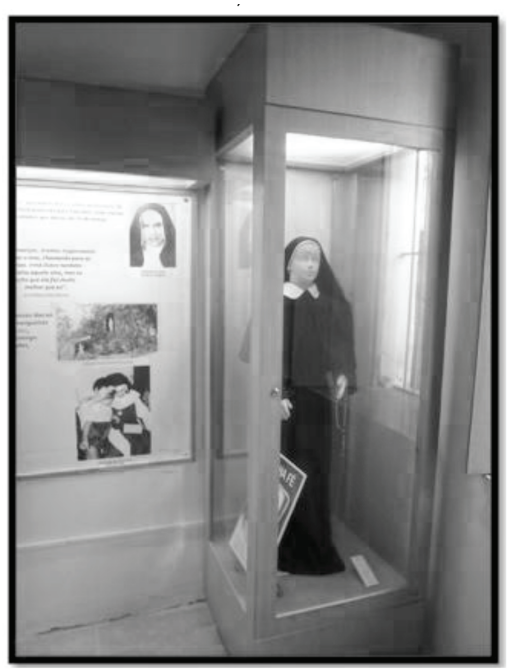

Foto: Ivan Rêgo Aragão.

Demarcar a trajetória de vida da Irmã Dulce a partir dos lugares que a religiosa esteve e lembrança de quem dividiu momentos com ela foi o desafio abraçado pelas Obras Sociais Irmã Dulce, mantenedora da missão e memória da religiosa. Reconhecendo o Convento do Carmo, de São Cristóvão, como lugar de sua formação, é que a instituição sediada em Salvador estabeleceu parcerias para instalação do pequeno memorial contando sua vida e presença em São Cristóvão na década de 1930. 
Dona Olga Braga dos Santos (1922/2015) colaborou na inauguração do espaço museal que parece pequeno ao visitante. Dona Olga sempre morou vizinha ao Convento e ainda menina recepcionou Maria Rita Lopes Pontes quando ela chegou à manhã de 9 fevereiro de 1933. No seu depoimento, recorda da religiosa baiana: "Ela simpatizou comigo [...] como a madre deixava eu entrar, eu ajudava as freiras nas atividades diárias [...] chorei tanto quando ela foi embora que pensei que ia morrer" (BARJAS, 2009).

Uma biografia a partir de textos e imagens, réplicas de seu hábito, da boneca Célica que ilustrou tantas cenas cotidianas, figuram na exposição. Para além da pequena sala Irmã Dulce, as dependências de todo o complexo carmelita deve ser compreendido como memorial. O claustro e seu jardim, a gruta, assim como o sino e mesmo a cela (seu quarto) permanecem nos relatos e lembranças. Ainda hoje, é possível encontrar o mesmo convento carmelitano, na integridade e originalidade narrada pela Irmã Maria das Neves, companheira de Irmã Dulce naquele distante 1933.

Claustro, escadaria, celas:

[...] logo depois da igreja, ao lado vinha o claustro com suas colunas, no centro do claustro um jardim com canteiros e toda aquela parte rodeada pelo clastro. Havia duas escadas, uma escada que era próxima da igreja que nós subíamos para o primeiro andar do Convento onde havia o dormitório das postulantes. () E do outro lado do claustro havia também uma escadaria do lado direito, essa escadaria conduzia até a sala de costura, era um corredor comprido, longo... esse corredor atravessava toda aquela parte e ao lado do corredor haviam também o que chamava-se antigamente "as celas", todas com cortinas na frente; o dormitório das noviças passava por uma porta larga e se estendia por toda aquela área. Ali havia os banheiros, ali também havia naquele andar o quarto da provincial, da comissária onde cuja porta por muitas vezes a gente batia pra falar com ela ou pedir orientação. (RIBEIRO, 2000).

Sino:

Nós noviças éramos as encarregadas de tocar esse sino, cada noviça tinha um período de tempo e era encarre- gada de tocar aquele badalar, aquele sino pra missa.. Foi o nervoso que eu tive de badalar aquele sino, Irmã Dulce também badalou aquele sino, mas eu acho que ela fez muito melhor do que eu [...].(RIBEIRO, 2000).

Sítio:

Ela participava das nossas idas ao sitio, que era um terreno de muitas fruteiras, muitas mangueiras, a mestra nos mandava então, nos dava uma tarde de folga aos domingos. A alegria de Irmã Dulce era de dentro o espirito da comunição e fraternismo []. Eram momentos de lazer que nós tinhamos depois de uma semana toda de trabalho, de oração, de rigor, mas tudo feito com muita alegria, com muito entusiasmo [...] os fins de semana colaborava muito na nossa formação religiosa e acredito que isso serviu muito pra Irmã Dulce, porque ela expressava sua alegria de participar dessas tardes recreativas, no sítio do Convento do Carmo. (RIBEIRO, 2000).

\subsection{HORTO IRMÃ DULCE}

Atualmente, o lugar é chamado de Gruta de Oração da Irmã Dulce. Quando ela chegou ao convento o lugar já era usado para meditações e orações, conforme lemos em suas cartas. Seu pai, Dr. Augusto, teria levado dali algumas folhas e flores na ocasião da sua vestição, no dia 15 de agosto de $1934^{13}$. Trata-se de uma elevação escavada num ambiente arborizado, com fonte e pedras compondo um nincho. Nele, a representação da imagem de Nossa Senhora de Lurdes e as crianças que testemunharam o milagre que a notabilizou.

\section{CONSIDERACÕES FINAIS}

A presença da Irmã Dulce no complexo arquitetônico carmelita do século XVII é passível de demarcação, seja a partir das lembranças dos que dividiram com ela o convívio em um ano e meio do seu postulantado e noviciado, seja a partir dos documentos gerados, suportes que concretizaram o Memorial Irmã Dulce em 2009. Um lugar para lembrar quem foi "o Anjo Bom da Bahia”, “a Mãe e Santa dos Pobres”.

13. Carta de Irmã Dulce para Elisabeth Maria Gertrudes Tomblock. 
0 rito de lembrar, a necessidade ou a possibilidade de reconstituir os dias de Irmã Dulce no convento secular recebeu, portanto um altar, centro de referência ou lugar de memória que deve transpor as paredes da "salinha” afinal as pessoas é que são portadoras de memórias, afetos e conhecimentos. "Os lugares de memória são, antes de tudo, restos. A forma extrema onde subsiste uma consciência comemorativa numa História que a chama, porque ela a ignora", assegura Nora (1993, p. 12).

No jogo de lembrar/esquecer, as sociedades reestabelecem vínculos com o passado fundamentais para o processo de construção identitária. A passagem de Irmã Dulce por São Cristóvão, tornou-se tempo e espaço da sua experiência compartilhada com outros (as), a gênese da sua vida exemplar guardada na memória da cidade e de seus moradores.

\section{REFERÊNCIAS}

Carta de Irmã Dulce para Elisabeth Maria Gertrudes Tombrock. São Cristóvão, 27 de agosto de 1933. Arquivo das Obras Sociais Irmã Dulce. Manuscrita.

BARJAS, Daniel. Entrevista com Olga Braga dos Santos. Ninho Roda o Brasil, 2009. São Cristóvão, 2009.

FRAGATA, Thiago. Epistolário de Irmã Dulce. Revista do Instituto Histórico e Geográfico de Sergipe. Aracaju, n.37, 2008.p.341-351.

FRAGATA, Thiago. Ascartas de Irmã Dulce. Publicado no Jornal da cidade. Aracaju, 24/08/2008. Monografias. com. Disponível em: <http://br.monografias.com/ trabalhos913/cartas-irma-dulce/cartas-irma-dulce. shtml>. Acesso em: 13 jan. 2015.

HALBWACHS, Maurice. La memoria colectiva. Trad. de Inés Sancho-Arroyo. Zaragoza: Prensas Universitarias de Zaragoza, 2004.
MENEZES, Ulpiano B. de. A história cativa da memória? Para um mapeamento da memória no campo das ciências sociais. Revista do Instituto de Estudos Brasileiros, n.34, SP: USP, 1992. p.9-24.

NORA, Pierre. Entre memória e história. A problemática dos lugares. Revista Projeto História. n.10. São Paulo: Pontificia Universidade Católica, 1993. p.7-28.

OBRAS SOCIAIS IRMÃ DULCE (OSID). Irmã Dulce dos pobres. Disponível em: <https://www.irmadulce.org. br>. Acesso em: 13 jan. 2015.

ORAZEM, Roberta Bacellar. Arte colonial sergipana: análise dos elementos artísticos das igrejas da Ordem Terceira e Conventual do Carmo em São Cristóvão/SE. 2006. Monografia (Licenciatura em Artes Visuais) Universidade Federal de Sergipe, São Cristóvão, 2006.

POLLAK, Michel. Memória e Identidade Social. Trad. Monique Augras. Revista dos Estudos Históricos, v.5, n.10, Rio de Janeiro: FGV/CPDOC, 1992. p.1-15.

REDE BAHIA de televisão. Obras sociais revelam quem recebeu milagre atribuído à Irmã Dulce. G1, 13/05/2011. Disponível em: <http://g1.globo.com/ bahia/noticia/2011/05/identidade-da-mulher-querecebeu-milagre-de-irma-dulce-e-revelada.html>. Acesso em: 13 jan. 2015.

REVISTA ISTO É. Irmã Dulce - a religiosa do século, ed.especial, n.6, São Paulo, 2000.

RIBEIRO, Osvaldo Gouveia. Entrevista com Irmã Maria das Neves. João Pessoa/PB, 16 de abril de 2000. Processo histórico de beatificação de Irmã Dulce. Assessoria da Memória e Cultura das Obras Sociais Irmã Dulce (OSID).

SILVA FILHO, José Thiago da. Entrevista com Olga Braga dos Santos. São Cristóvão, 14 nov. 2006. 
Recebido em:07 de Fevereiro de 2015

Avaliado em: 17 de Junho de 2015

Aceito em: 25 de Junho de 2015
1. Mestre em Cultura e Turismo/Universidade Estadual de Santa Cruz (UESC-Bahia); Especialista em História e Cultura no Brasil/Universidade Gama Filho (UGF); Membro do Grupo de Pesquisa Sociedade \& Cultura (NPGEO/UFS/CNPq) e da Associação Brasileira de História das Religiões (ABHR). E-mail: regoivan70@gmail.com

2. Especialista em História Cultural pela Universidade Federal de Sergipe (UFS); Graduado em História pela mesma universidade; Membro do Instituto Histórico e Geográfico de Sergipe (IHGSE) do Grupo de Pesquisa Culturas, Identidades e Religiosidades (GPCIR/UFS/CNPq) e do Grupo de Pesquisa Sergipe Oitocentista (SEO/CNPq). Email: thiagofragata@gmail.com 